Published in final edited form as:

Ecol Econ. 2017 July ; 137: 29-36. doi:10.1016/j.ecolecon.2017.02.020.

\title{
Valuing Air Quality Using Happiness Data: The Case of China1
}

\author{
Xin Zhang, \\ National School of Development, Peking University
}

Xiaobo Zhang, and

National School of Development, Peking University, International Food Policy Research Institute

\section{Xi Chen}

School of Public Health and Department of Economics, Yale University

\begin{abstract}
This paper estimates the monetary value of cutting PM2.5, a dominant source of air pollution in China. By matching hedonic happiness in a nationally representative survey with daily air quality data according to the dates and counties of interviews in China, we are able to estimate the relationship between local concentration of particulate matter and individual happiness. By holding happiness constant, we calculate the tradeoff between the reduction in particulate matter and income, essentially a happiness-based measure of willingness-to-pay for mitigating air pollution. We find that people on average are willing to pay $¥ 258$ (\$42, or $1.8 \%$ of annual household per capita income) per year per person for a 1\% reduction in PM2.5.
\end{abstract}

\section{Keywords \\ willingness to pay; hedonic happiness; air pollution; China}

\section{JEL Codes}

Q51; Q53; I31

\section{Introduction}

\begin{abstract}
Air pollution poses a substantial physical and social threat to human beings. ${ }^{2}$ As such, government agencies are often called upon to implement environmental regulations to
\end{abstract}

\footnotetext{
${ }^{1}$ We are grateful to have access to the national sample of the China Family Panel Studies (CFPS), which is funded by 985 Program of Peking University and carried out by the Institute of Social Science Survey of Peking University. Financial support from the Yale Macmillan Center Faculty Research Award on air pollution study (2013-2015), the National Institute of Health (Grant Number: 1 R03 AG048920) (2014-2016), the U.S. Federal PEPPER Center Career Development Award (2016-2018), and James Tobin Summer Research Fund at Yale Economics Department are acknowledged. The views expressed herein and any remaining errors are the authors' and do not represent any official agency.

Corresponding author: Xi Chen, Department of Health Policy and Management and Department of Economics, Yale University, New Haven, CT 06520, xi.chen@yale.edu.

Publisher's Disclaimer: This is a PDF file of an unedited manuscript that has been accepted for publication. As a service to our customers we are providing this early version of the manuscript. The manuscript will undergo copyediting, typesetting, and review of the resulting proof before it is published in its final citable form. Please note that during the production process errors may be discovered which could affect the content, and all legal disclaimers that apply to the journal pertain.
} 
reduce air pollution. When introducing more stringent regulations, governments need to gauge the monetary value of better air quality so as to compare it with the cost of environmental regulations (Greenstone and Jack 2014). However, because air quality is not a standard good for sale, evaluating its value is a great challenge.

There are three major approaches to valuing air quality: the hedonic approach (Smith and Huang 1995; Chattopadhyay 1999; Chay and Greenstone 2005; Bayer and Timmins 2009; Yusuf and Resosudarmo 2009), the contingent valuation method (CVM) (Alberini and Krupnick 1998; Kwak, Yoo and Kim 2001; Zhai and Suzuki 2008; Vasquez et al. 2009; Wang, Xie and Li 2010; Wang et al. 2013), and the happiness approach.

Each method is associated with its own advantages and disadvantages. The hedonic approach infers the value of air quality from the differences in property values across regions with varying air quality after controlling for many observable factors. The main problem with this approach is location sorting: those who are more concerned about air pollution may move into less polluted areas in the first place, rendering the locational choice endogenous and causing biased estimates on the value of air quality.

The CVM directly surveys people regarding their willingness to pay for better air quality. However, this approach is subject to strategic responses, the ways of questions being framed, and the initial hypothetical monetary value adopted to start the survey. Consequently, estimates based on CVM often yield a wide range of willingness to pay for better air quality. For example, in China, the estimates of willingness to pay for smog mitigation range from $¥ 428$ (Wang et al. 2015) to as large as ¥1,590 per year (Sun, Yuan and Yao 2016).

It has been well documented in the literature that happiness is positively associated with household annual income at a given time (Knight, Song, and Gunatilaka 2009; Knight and Gunatilaka 2010,2011) but negatively affected by air pollution (Welsch 2007; Rehdanz and Maddison 2008; MacKerron and Mourato 2009; Luechinger 2010; Ferreira et al. 2013). There is a tradeoff between income growth and worsening air pollution. Based on the findings in the literature, our happiness approach computes willingness to pay based on the average marginal rate of substitution between air pollution and annual income, holding happiness constant in regressions of happiness (stated well-being) on air quality. Since this approach relies on surveys evaluating peoples' stated well-being and does not directly ask about their valuations on public goods per se, strategic responses are largely avoided. In addition, this approach, often based on large representative surveys, can be used to assess heterogeneities in valuations across different subgroups. The happiness approach is not without its own weaknesses. For example, it treats stated well-being as a proxy for utility and makes interpersonal comparisons among respondents. Moreover, this approach only applies to public goods, such as air pollution, which vary across individuals in any given location and time. ${ }^{3}$

${ }^{2}$ For example, cognitive test scores (Bharadwaj et al. 2014; Ham et al. 2014; Marcotte 2016), human capital formation (Ebenstein et al. 2016), productivity of indoor workers (Chang et al. 2014; Li, Liu and Salvo 2015), mental health and subjective well-being (Zhang, Zhang and Chen 2015).

${ }^{3}$ See an excellent discussion about advantages and disadvantages of these approaches by Levinson (2012). 
There is a burgeoning body of studies valuing air quality based on the happiness approach. However, most studies rely on aggregated air quality data spanning a rather long period, such as one year (Welsch 2006; Luechinger 2009, 2010; Menz and Welsch 2010; Menz 2011; Chen and Shi 2013; Ambrey 2014). Consequently, the aggregated long-term air pollution used in analyses may not reflect the actual exposure at the time of interview faced by survey subjects, resulting in measurement errors.

Moreover, the literature primarily uses life satisfaction as a measure of happiness (Welsch 2006; MacKerron and Mourato 2009; Luechinger 2009, 2010; Menz and Welsch 2010; Menz 2011; Ferreira 2013; Ambrey 2014). Life satisfaction, an evaluative happiness measure, reflects one's overall assessment of life in the long term. While hedonic happiness, on the other hand, refers to moment-to-moment experienced utility and has a more direct link to immediate emotions and affections. It is necessary to test both evaluative and hedonic happiness as these two measures could yield different results (Deaton and Stone 2013). Our paper employs hedonic happiness, which has been less studied in the literature, and links it to daily air quality data. ${ }^{4}$

Furthermore, most existing studies focus only on a single air pollutant. In this study, we simultaneously estimate the willingness to pay for several major air pollutants, including but not limited to particulate matter with a diameter smaller than 2.5 micrometers (PM2.5). Because nationwide PM2.5 monitoring data was not released in China until 2014, our study is among the first to assess the monetary value of reducing PM2.5 in China. Previous studies have shown that finer particulate matter, such as PM2.5, tends to be more detrimental to health than larger particulates, such as those with a diameter smaller than 10 micrometers (PM10) (Stanek et al. 2011, Cao et al. 2014; Pal et al. 2016). PM10 is usually trapped in the upper airways and can be cleared by mucociliary mechanisms. However, due to its miniature size, PM2.5 can penetrate lungs at the alveolar level, translocate directly through the alveolar capillaries into the circulatory system, and leave toxic substances in the blood, causing cumulative damage to the body (Stanek et al. 2011). Exposure to PM2.5 may affect human development in the long run (Ebenstein et al. 2016). We focus on PM2.5 because it is in high concentrations and associated with greater public awareness in China.

Air pollution is generally worse in some developing countries (Chen et al. 2013; Greenstone and Hanna 2014; Tanaka 2015). For example, almost half of the Chinese population is exposed to PM2.5 at a level beyond the highest hazard threshold in the United States. Recently, the choking smog has galvanized public opinion in China, calling for more stringent environment regulations (The Economist 2015). Given that air pollution is ubiquitous in some developing countries such as Bangladesh, India and Nepal, the study on China may shed some light for other developing countries as well. ${ }^{5}$

We merge a nationally representative survey - the China Family Panel Studies (CFPS) with newly released daily air quality data that contain rich information on six main

\footnotetext{
${ }^{4}$ As noted in Zhang, Zhang and Chen (2015), the level of short-term air pollution is negatively associated with hedonic happiness, while it has little to do with life satisfaction.

5 According to the 2016 Environmental Performance Index published by the Yale University, the world's top five most air polluted countries are Bangladesh, China, India, Nepal and Laos.
} 
pollutants and weather conditions at the time and county of each interview. The wellmatched air quality measure precisely captures environmental amenities that interviewees were exposed to. A key assumption for our identification strategy is that day-to-day fluctuations of air quality in a given county have little to do with the characteristics of individual respondents. More generally, under the assumption that sorting in response to air pollution occurs more slowly than changes in happiness, high-frequency variations in air pollution over a short period of time in conjunction with local area fixed effects are literally random to survey subjects. ${ }^{6}$

We find that the concentration of particulate matter is negatively associated with people's hedonic happiness. People on average are willing to pay $¥ 539$ ( $\$ 88$, or $3.8 \%$ of annual household per capita income) for a $1 \mu \mathrm{g} / \mathrm{m}^{3}$ reduction in PM2.5 per year per person. ${ }^{7}$ In other words, a one SD decline in PM2.5 raises an average person's happiness by an amount worth $¥ 49$ (\$8) per day. Our estimates are robust and consistent with comparable studies and may provide the first estimate of WTP for PM2.5 in China.

The rest of the paper is organized as follows. Section 2 describes the data. Section 3 lays out the empirical strategy. Section 4 presents our main findings, including robustness checks and heterogeneous tests. Finally, section 5 concludes.

\section{Data}

For happiness measures, we rely on the China Family Panel Studies (CFPS), a nationally representative survey of Chinese communities, families, and individuals. The CFPS is funded by Peking University and carried out by the Institute of Social Science Survey of Peking University. Respondents in the third wave of the CFPS survey conducted in year 2014 were asked to report the extent to which they felt it was difficult to be cheered up in the past month, ranging from 0 (almost every day) to 4 (never). The answer to this question forms the basis for the dependent variable. The higher the number, the happier the respondents were. In addition to happiness measures, the CFPS survey collects rich information at multiple levels, allowing us to control for a wide range of covariates to be introduced in the next section. Moreover, the CFPS contains information about geographic counties and dates of interviews for all respondents, which enables us to precisely match individual happiness measures in the survey to local air quality data.

The air pollution measures come from the daily air quality report published by the Ministry of Environmental Protection of China (MEP). The report, which was not released until 2014, covers 947 monitoring stations including longitude and altitude information for each station. Six pollutants, including PM2.5, PM10, carbon monoxide (CO), nitrogen dioxide $\left(\mathrm{NO}_{2}\right)$, daily maximum ozone $\left(\mathrm{O}_{3}\right)$ and sulfur dioxide $\left(\mathrm{SO}_{2}\right)$, are used in our analysis. Figure A1 and Figure A2 indicate that particulate matters (PM2.5 and PM10) are highly concentrated and are dominant sources of air pollution on most days in China.

\footnotetext{
${ }^{6}$ Several studies have made such assumption in their analyses, e.g. Levinson (2012) and Currie et al. (2014) provide an excellent review of this approach.

$7 ¥ 539$ corresponds to $\$ 87.74$ using the average 2014 exchange rate $1 \mathrm{USD}=6.1434 \mathrm{CNY}$.
} 
We also include rich weather data in our analysis to help isolate the impact of air pollution from other weather patterns. The weather data come from the National Climatic Data Center under the US National Oceanic and Atmospheric Administration. The dataset contains consecutive daily records of rich weather conditions from 402 monitoring stations in China, such as temperature, precipitation, wind speed, and an indicator for bad weather. ${ }^{8}$ Sunshine duration data is obtained from the 194 monitoring stations of China National Meteorological Information Center. Sunshine may affect individuals' moods, social behavior, and health (Cunningham 1979; Wolfson 2013).

To merge the survey data with the air pollution readings, we calculate the weighted average values of all the monitoring stations within $60 \mathrm{~km}$ to the centroids of each CFPS county, where the weights are equal to the inverse of distance between stations and the county centroids. In the absence of stations within this radius, we obtain air quality from the nearest station within 100 kilometers. Weather controls are matched in the same way. ${ }^{9}$ The binary indicator for bad weather and the sunshine duration are obtained from the nearest monitoring station regardless of the distance.

The 2014 wave of CFPS has 31,665 individuals, of which 22,896 could be matched to air quality and weather data within 100 kilometers. ${ }^{10}$ Due to 51 missing values for hedonic happiness and 1,256 missing values for household demographics, the final dataset for analyses includes 21,589 observations. ${ }^{11}$

\section{Empirical Strategy}

Our baseline econometric specification is as follows:

$$
H_{i j t}=\alpha P_{j t}+\beta \ln Y_{i j t}+X_{i j t}^{\prime} r+W_{j t}^{\prime} \phi+\delta_{j}+\eta_{t}+\varepsilon_{i j t}
$$

The dependent variable $H_{i j t}$ is the self-reported hedonic happiness of respondent $i$ in county $j$ at date $t$. The key variable $P_{j t}$ is the air pollution in county $j$ at date $t . \ln Y_{i j t}$ is the $\log$ form of household per capita income. We control for a set of demographic correlates of happiness $X_{i j t}$ including age and its squared term, gender, marital status, years of education, unemployment status, party membership, and health status. We also control for a vector of rich weather conditions $W_{j t}$ involving sunshine duration, mean temperature and its squared term, total precipitation, mean wind speed, and a dummy for bad weather on the day of interview, to mitigate the concern that they are correlated with both hedonic happiness and air quality and therefore might bias our estimations. $\delta_{j}$ represents county fixed effect; $\eta_{t}$

\footnotetext{
${ }^{8} \mathrm{Bad}$ weather includes fog, rain/drizzle, snow/ice pellets, hail, thunder, and tornadoes/funnel clouds.

${ }^{9}$ See Ziebarth et al. (2014) for an example of this interpolation approach. Our baseline results are robust to matching using narrower radiuses, but the current set of results is reported to retain more observations in the analysis. Meanwhile, these baseline results are robust to alternative weights, including inverse of the square root distance or squared distance between the monitoring stations and the county centroids.

${ }^{10}$ Counties unmatched to any air quality or weather monitoring station within 100 kilometers are dropped. The matching rate $72.3 \%$ $(=22,896 / 31,665)$ is within a reasonable range. For example, a highly comparable study, Levinson $(2012)$, was able to retain $52.3 \%$ of the observations when matching the U.S. General Social Survey with PM10 readings from the EPA's Air Quality System.

${ }^{11}$ There are no strong significant differences between the various groups based on key variables. The results are available upon request.
} 
indicates month and day-of-week fixed effects. $\varepsilon_{i j t}$ is the error term. Standard errors are clustered at the county level. Table 1 describes key variables and their summary statistics.

By totally differentiating equation (1) and holding hedonic happiness constant (i.e., setting $d H=0$ ), we calculate the average marginal rate of substitution between air pollution and household per capita income, $\partial Y /\left.\partial P\right|_{d H=0}=-Y \hat{\alpha} / \hat{\beta}$, to assess a money metric value of air quality. This value is also known as "willingness to pay" (WTP), which represents the amount of annual income that people, on average, are willing to pay for a one-unit improvement in daily air pollution.

Figure A3 shows the distribution of interview dates for the CFPS 2014 national sample, which spans from July to December. Most surveys were conducted in July and August, as these two months largely overlapped with summer breaks during which many college students were hired as numerators for the CFPS. Our identification relies on variations in exposure to air pollution across similar respondents living in the same county in the same year. Since surveys lasted more than four months in most counties, there is substantial within-county variation of air quality in the survey period. ${ }^{12}$

\section{Results}

\subsection{Baseline Results}

Table 2 reports the baseline estimates for various measures of air quality. Column (1) begins with PM2.5. Hedonic happiness decreases with PM2.5 on the day of interview and increases with annual household per capita income. A $1 \mu \mathrm{g} / \mathrm{m}^{3}$ increase in PM2.5 leads to a decline in happiness by $0.565 \%$. A $1 \%$ increase in household per capita income raises happiness by $0.15 \%$. As reported in the last row of Table 2, according to a back-of-the-envelope calculation, people are on average willing to pay $3.8 \%$ of their annual income for a $1 \mu \mathrm{g} / \mathrm{m}^{3}$ reduction in PM2.5 on the day of the interview. By plugging in $-0.565 \%$ for $\hat{\alpha}, 0.15 \%$ o for $\hat{\beta}$, $14,313.90$ for the mean household per capita income (in Chinese yuan), WTP corresponds to $\partial Y / \partial P=¥ 539$, which indicates that a $1 \mu \mathrm{g} / \mathrm{m}^{3}$ decline in PM2.5 raises an average person’s happiness by an amount worth $¥ 539$ ( $\$ 87.74$ ) per year per person, or $¥ 1.48$ per day per person. To put this into context, note that the standard deviation (hereafter SD) of PM2.5 is $33.258 \mu \mathrm{g} / \mathrm{m}^{3}$. The WTP amounts to $¥ 49$ (=33.258x¥1.48) for a one SD decline in PM2.5 per day. Besides, the sample mean of PM2.5 is $47.86 \mu \mathrm{g} / \mathrm{m}^{3}$, which means people on average are willing to pay $¥ 258$ ( $\$ 42$, or $1.8 \%$ of annual household per capita income) for a $1 \%$ reduction in PM2.5 per year per person.

Column (2) identifies the impact of particulate matter with a diameter between 2.5 and 10 micrometers (PM2.5-10). Unlike the coefficient for PM2.5, the coefficient for PM2.5-10 is insignificant and the calculated WTP is quite small. The different estimates between PM2.5 and PM2.5-10 suggest that people are much more willing to pay for a reduction in finer

\footnotetext{
${ }^{12}$ Although most interviews were conducted in summer, the interview period often lasted for more than four months in each county, sometimes extended to November and December, when air quality is generally worse. Besides, a weighted regression giving each winter month (November and December) and each non-winter month (July to October) an equal weight indicates that the timing of the survey gives us enough variations, and the underestimation of WTP, if any, is small. The result is available upon request.
} 
particulates (PM2.5) compared to coarse particulates (PM2.5-10). Considering that the WTP literature in China has largely focused on coarse particulates, this finding highlights the importance of giving special attention to finer particulates.

Column (3) estimates the WTP for a $1 \mu \mathrm{g} / \mathrm{m}^{3}$ reduction in PM10 ${ }^{13}$. Calculations based on the point estimate suggest a WTP of $¥ 334$ (or $2.3 \%$ of annual income) for a $1 \mu \mathrm{g} / \mathrm{m}^{3}$ reduction in PM10 per year. Similarly, Chen and Shi (2013) find that Chinese residents are willing to pay $¥ 355$ (or $2.8 \%$ of annual income) for a $1 \mu \mathrm{g} / \mathrm{m}^{3}$ reduction in PM10 per year. Levinson (2012) finds a WTP of $\$ 891$ (or $2.1 \%$ of annual income) for U.S. residents. ${ }^{14}$ Although people in the U.S. on average seem to be willing to pay a much higher amount in absolute terms, Chinese residents are more willing to pay a larger share of their income for air pollution mitigation than their U.S. counterparts.

Column (4) presents results for CO. The coefficient on CO is statistically insignificant. The corresponding WTP is only $¥ 5$ for a one SD reduction per day, much less than the WTP for reduction in PM2.5. The difference may stem from the fact that $\mathrm{CO}$ is odorless, colorless and therefore less noticeable. Besides, $\mathrm{CO}$ only becomes a dominant source of air pollution for two percent of days throughout the year (Figure A2).

Similarly, the coefficient on $\mathrm{NO}_{2}$ presented in Column (5) is statistically insignificant and the estimated WTP is $¥ 10$ for a one SD reduction per day. According to the National Ambient Air Quality Standards (NAAQS) established by the United States Environmental Protection Agency (EPA), the primary and secondary standard for $\mathrm{NO}_{2}$ is $53 \mathrm{ppb}(100 \mu \mathrm{g} /$ $\left.\mathrm{m}^{3}\right) .{ }^{15}$ In our sample, the mean and SD are both below this safety level, and thus $\mathrm{NO}_{2}$ is not considered a major pollutant in China.

Column (6) estimates WTP for ozone. Though the coefficient on ozone is still statistically insignificant, the magnitude of WTP amounts to $¥ 42$ for a one SD reduction per day. Ozone is a dominant source of air pollution for more than 10 percent of days each year (Figure A2), but in general the concentration level only causes discomfort among vulnerable populations, such as those with lung diseases. ${ }^{16}$

The last column reports results for $\mathrm{SO}_{2}$. Several papers examine the effects of annual average $\mathrm{SO}_{2}$ on life satisfaction. For example, the average marginal WTP estimated in Luechinger (2010) is $\$ 312$ (1.1\% of annual income) for a $1 \mu \mathrm{g} / \mathrm{m}^{3}$ reduction in $\mathrm{SO}_{2}$ per year. ${ }^{17}$ In our case, the coefficient on $\mathrm{SO}_{2}$ is statistically insignificant and the corresponding estimated WTP is $¥ 664$ (4.6\% of annual income) for a $1 \mu \mathrm{g} / \mathrm{m}^{3}$ reduction in pollution per year.

\footnotetext{
${ }^{13}$ Mathematically, the WTP for PM10 should be a weighted average of WTPs for PM2.5 and PM2.5-10, where the weight depends on the PM composition in the air.

${ }^{14} \$ 891$ corresponds to $¥ 5,474$.

15 The Clean Air Act identifies two types of national ambient air quality standards. Primary standards provide public health protection, including protecting the health of "sensitive" populations such as asthmatics, children, and the elderly. Secondary standards provide public welfare protection, including protection against decreased visibility and damage to animals, crops, vegetation, and buildings.

16 Source: https://www3.epa.gov/airnow/aqi-technical-assistance-document-dec2013.pdf.

$17 \$ 312$ is approximately $¥ 1,917$.
} 


\subsection{Robustness Checks}

In this section, we perform a set of regressions to check the robustness of our main results. We focus on PM2.5 because it is associated with more detrimental effects on health and greater public awareness. Table 3 presents alternative specifications. Column (1) replicates the baseline results in Column (1) of Table 2 for ease of comparison. Column (2) adds a control variable, the PM2.5 level on the day prior to the interview date, to account for the lagged effect of pollution. After its inclusion, the negative effect of contemporaneous PM2.5 amplifies, yielding higher WTP for PM2.5 reductions.

Daily PM2.5 on the date of interview may reflect longer-term pollution in a county. To mitigate this concern, column (3) adds average local PM2.5 over the month when the survey was conducted to control for the long-term air pollution. The coefficient for monthly PM2.5 level is negative and insignificant, while daily PM2.5 remains significant and is of similar size, which confirms that day-to-day fluctuations in air quality drive our results. The estimate of WTP for a one SD reduction in PM2.5 per day slightly declines from $¥ 49$ to $¥ 48$.

Column (4) estimates equation (1) using an ordered probit model. The coefficient on PM2.5 remains negative and significant. The calculated WTP for a one SD change in PM2.5 per day is slightly higher at $¥ 58 .{ }^{18}$ Column (5) uses the log form of PM2.5 instead of the linear form of PM2.5 in the specification. Again, there is no substantial change in the measured WTP. ${ }^{19}$ Overall, our baseline results are robust to several specifications.

Another potential estimation issue is that the concentrations of various pollutants are often highly correlated and not distinguishable to survey subjects. ${ }^{20}$ Therefore, estimated monetary values for a certain pollutant may inherently embody payment to other pollutants. To address this concern, we run the baseline result for PM2.5 by including daily measures of PM2.5-10, $\mathrm{CO}, \mathrm{NO}_{2}$, ozone and $\mathrm{SO}_{2}$, respectively, as control variables. Table 4 reports the results. As shown in the table, the coefficients on PM2.5 and income remain essentially the same, while the additional pollutant is statistically insignificant, consistent with our baseline results in Table 2. Based on the coefficients for PM2.5 and income in the table, WTPs for a one SD change in PM2.5 per day remain within a reasonable range between $¥ 43$ and $¥ 56$.

While high-frequency variations in exposure to air pollution are random, awareness of air pollution may not be randomly assigned and may therefore drive the results we estimate. We address this concern in four major aspects. First, as reported in Column (6) of Table 3, the results are robust to further controlling for attitude towards pollution, ${ }^{21}$ which may mitigate the concern that larger WTP for PM2.5 than other air pollutants is simply because of more public awareness. Second, in fact air pollution may affect everyone's happiness without visually discernable change in the air. For example, the effect may work through many of the

\footnotetext{
${ }^{18}$ In the ordered probit model, the WTP is solved from the average marginal rate of substitution between pollution and income, keeping the latent variable constant.

${ }^{19}$ In this case, the WTP is equal to $\partial Y /\left.\partial P\right|_{d H-0}=-Y \hat{\alpha} / P \hat{\beta}$.

${ }^{20}$ Table A1 presents the correlations between the pollutants.

${ }^{21}$ The CFPS 2014 contains a host of questions to elicit people's attitudes toward major social issues in China, including environmental quality. The question for environmental issues is framed as "How severe do you think is the environmental problem in China?" The answer ranges from 0 (not severe at all) to 10 (very severe).
} 
psychological pathways, such as headache (Nattero and Enrico 1996), attention problems and fatigue (Kampa and Castanas 2008). Third, Chinese news media simultaneously release information on Air Quality Index (AQI) as well as major set of pollutants without a focus on any specific pollutant. Considering that information on each pollutant is equally accessible but people only respond to PM2.5, we can rule out differential access to information as a confounder. Fourth, our happiness approach does not directly gauge the willingness-to-pay for each pollutant. When asked about happiness status, it is not framed as a question associated with any pollutant, avoiding strategic actions taken by respondents to manipulate their WTP.

Other robustness tests were also performed, and all these results are available upon request. First, we simultaneously control for PM2.5 on the day of interview and average PM2.5 in the past 30 days, and the effect of the contemporaneous PM2.5 is robust to this change in the specification, suggesting that people disproportionally care about contemporaneous air quality. Second, our results are robust to controlling for pre-existing mental health conditions.

In summary, all robustness tests provide us with a narrow range of WTPs between $¥ 43$ and $¥ 61$ associated with a one SD reduction in PM2.5 per day.

\subsection{Heterogeneous Effects}

This section examines the heterogeneous effect of air pollution on happiness and gauges WTPs across subgroups of population. First, responses to air quality may vary by education level. For example, lower education may restrict an individual's ability to acquire and digest information about air quality (Levinson 2012; Greenstone and Hanna 2014; Li, Folmer and Xue 2014). As revealed in Panel A of Table 5, more educated people are indeed willing to pay more for PM2.5 mitigations than less educated people.

Second, one's attitude toward pollution may also determine his/her reactions to air quality. CFPS 2014 includes a host of questions designed to assess peoples' attitudes toward major social issues in China, including environmental quality. ${ }^{22}$ Panel B divides the sample up by attitudes toward pollution. As shown in the panel, people who are critical about environmental issues are willing to pay more money for reducing PM2.5.

Further, we examine the differential impact on outdoor and indoor workers. While those working outdoors are exposed to more ambient air pollution, recent studies show that finer particulates can penetrate into a building and lead to a decline in indoor workers' productivity (Chang et al. 2014; He, Liu, and Salvo 2016). Panel C of Table 5 lists the estimates on outdoor and indoor workers separately. Perhaps because people who work indoors often earn much higher income than those who work outdoors, they are also willing to pay more for improved air quality. However, outdoor workers are willing to pay a slightly higher share of income.

\footnotetext{
${ }^{22}$ The question for environmental issues is framed as "How severe do you think the environmental problem is in China?" The answer ranges from 0 (not severe at all) to 10 (very severe). To mitigate the concern that some respondents may overstate or understate their general attitudes toward social issues, we calculate a normalized attitude score toward pollution by dividing the pollution assessment score by the average ratings of all eight questions. We divide our sample into two groups by the median of the normalized score.
} 
In addition, families with small children are expected to be more concerned about bad air quality. We divide the sample according to whether or not a family has a child younger than age six. As revealed in in Panel D of Table 5, families with young children are indeed willing to pay more for reduction in air pollution in both absolute amounts and in proportion to their incomes.

Finally, dividing the whole sample into two subsamples by yearly mean PM2.5 level, Columns (1) through (2) of Table A2 show that people in more polluted areas are willing to pay absolutely more for a one SD reduction in air pollution but lower income share for a 1 $\mu \mathrm{g} / \mathrm{m}^{3}$ reduction per year. We also identify the nonlinear effects of air pollution on happiness by dividing the concentrations of PM2.5 into four bins according to the air quality standards and assign each level an indicator that captures whether the air pollution level falls into this category (Column (3) of Table A2). Bin "PM2.5 $\leq 35 \mu \mathrm{g} / \mathrm{m}^{3}$ (Good)" is omitted as the reference group. The magnitude of the effect of " $35<\mathrm{PM} 2.5 \leq 75 \mu \mathrm{g} / \mathrm{m}^{3}$ " is basically the same as "75 $<$ PM2.5 $\leq 150 \mu \mathrm{g} / \mathrm{m}^{3}$ ". The effect of "PM2.5 $\geq 150 \mu \mathrm{g} / \mathrm{m}^{3}$ " doubles the size of "35<PM2.5 $\leq 75 \mu \mathrm{g} / \mathrm{m}^{3}$ ". The insignificance of the worst level of pollution may result from very few observations in the category and therefore its low statistical power to identify the effect (Figure A4). Our result indicates that the willingness-to-pay to reduce exposure to air pollution is subject to diminishing returns.

\section{Conclusion}

Matching hedonic happiness in CFPS, a nationally representative survey, with daily air quality data according to the dates and counties of the interviews, this paper uses a happiness approach to estimate the monetary value of air quality. We find that the concentration of particulate matter has a significant negative effect on hedonic happiness. On average, people are willing to pay $¥ 539$ ( $\$ 88$, or $3.8 \%$ of annual household per capita income) for a $1 \mu \mathrm{g} / \mathrm{m}^{3}$ reduction in PM2.5 per year per person. Our estimates are robust and consistent with comparable studies and may provide the first estimate of WTP for PM2.5 in China.

The population-weighted annual mean concentration of PM2.5 over 2014 in China is 68 $\mu \mathrm{g} / \mathrm{m}^{3}$, much larger than the air quality standards published by the EPA. ${ }^{23}$ In 2013 , the Chinese government implemented an important comprehensive policy to combating air pollution, namely “Air Ten Plan". This plan aims to reduce the concentration of PM by 10 percent in five years' time. ${ }^{24}$ Our results suggest that an average person can be willing to pay an amount equal to $¥ 3,665$ (US\$596.58) to achieve this goal. The actual WTP per year, however, will be much lower when we divide the 10 percent reduction in particulate matter in the time frame of five years.

Our results have important policy implications. China's 13th Five-Year Plan (2016-2020) strives for major progress in reducing air pollution. Specifically, the plan states that air quality of cities at and above the prefectural level must be good or excellent for 80 percent

\footnotetext{
${ }^{23}$ The annual mean PM2.5 data at the city level are obtained from the "China Environmental Statistical Yearbook 2015", and the population data come from "China City Statistical Yearbook 2015". The primary and secondary standards of annual mean PM2.5 are $12 \mu \mathrm{g} / \mathrm{m}^{3}$ and $15 \mu \mathrm{g} / \mathrm{m}^{3}$, respectively.

${ }^{24}$ Source: http://www.cleanairchina.org/file/loadFile/27.html.
} 
of days each year. ${ }^{25}$ The optimal environmental regulations depend on the tradeoffs between their benefits and costs. Our valuations of air quality provide useful information on the benefits of tightening environment regulations.

\section{Supplementary Material}

Refer to Web version on PubMed Central for supplementary material.

\section{References}

Alberini, Anna, Krupnick, Alan. Air Quality and Episodes of Acute Respiratory Illness in Taiwan Cities: Evidence from Survey Data. Journal of Urban Economics. 1998; 44:68-92.

Ambrey, Christopher L., Fleming, Christopher M., Chan, Andrew Yiu-Chung. Estimating the Cost of Air Pollution in South East Queensland: An Application of the Life Satisfaction Non-Market Valuation Approach. Ecological Economics. 2014; 97:172-181.

Bayer P, Keohane N, Timmins C. Migration and Hedonic Valuation: the Case of Air Quality. Journal of Environmental Economics and Management. 2009; 58(1):1-14.

Bharadwaj, Prashant, Gibson, Matthew, Zivin, Joshua Graff, Neilson, Christopher A. Gray Matters: Fetal Pollution Exposure and Human Capital Formation. 2014. NBER Working Paper No. 20662

Cao, Chen, Jiang, Wenjun, Wang, Buying, Fang, Jianhuo, Lang, Jidong, Tian, Geng, Jiang, Jingkun, Zhu, Ting F. Inhalable Microorganisms in Beijing's PM2.5 and PM10 Pollutants during a Severe Smog Event. Environmental Science \& Technology. 2014; 48:1499-1507. [PubMed: 24456276]

Chang, T., Zivin, JG., Gross, T., Neidell, M. Particulate Pollution and the Productivity of Pear Packers. Cambridge, MA, US: National Bureau of Economic Research; 2014. NBER Working Paper 19944

Chattopadhyay S. Estimating the Demand for Air Quality: New Evidence Based on the Chicago Housing Market. Land Economics. 1999; 75(1):22-23.

Chay, Kenneth, Greenstone, Michael. Does Air Quality Matter? Evidence from the Housing Market. Journal of Political Economy. 2005; 115(2):376-424.

Chen Y, Ebenstein A, Greenstone M, Li H. Evidence on the Impact of Sustained Exposure to Air Pollution on Life Expectancy from China's Huai River Policy. PNAS. 2013; 110:12936-12941. [PubMed: 23836630]

Chen, Yongwei, Shi, Yupeng. Xingfu Jingjixue Shijiao Xia De Kongqi Zhiliang Dingjia. Economic Science. 2013; 6:77-88.

Cunningham MR. Weather, Mood, and Helping Behavior: Quasi Experiments with the Sunshine Samaritan. Journal of Personality and Social Psychology. 1979; 37(11):1947-1956.

Currie J, Graff Zivin J, Mullins J, Neidell M. What Do We Know About Short- and Long-Term Effects of Early-Life Exposure to Pollution? Annual Review of Resource Economics. 2014; 6(1):217-247.

Deaton A, Stone AA. Two Happiness Puzzles. American Economic Review. 2013; 103:591-597. [PubMed: 25110356]

Ebenstein A, Lavy V, Roth S. The Long-Run Economic Consequences of High-Stakes Examinations: Evidence from Transitory Variation in Pollution. American Economic Journal: Applied Economics. 2016; 8(4):36-65.

Ferreira, Susana, Akay, Alpaslan, Brereton, Finbarr, Cuñado, Juncal, Martinsson, Peter, Moro, Mirko, Ningal, Tine F. Life Satisfaction and Air Quality in Europe. Ecological Economics. 2013; 88:1-10.

Greenstone M, Hanna R. Environmental Regulations, Air and Water Pollution, and Infant Mortality in India. American Economic Review. 2014; 104(10):3038-3072.

Greenstone M, Jack BK. Envirodevonomics: A Research Agenda for an Emerging Field. Journal of Economic Literature. 2015; 53(1):5-42.

Ham, John C., Zweig, Jacqueline S., Avol, Edward. Pollution, Test Scores and Distribution of Academic Achievement: Evidence from California Schools 2002-2008. 2014. Working paper

${ }^{25}$ Source: http://language.chinadaily.com.cn/2016-03/18/content_23944369_2.htm. 
Kwak, Seung-Jun, Yoo, Seung-Hoon, Kim, Tai-Yoo. A Constructive Approach to Air Quality Valuation in Korea. Ecological Economics. 2001; 38:327-344.

Knight J, Gunatilaka R. The Rural-urban Divide in China: Income but Not Happiness? Journal of Development Studies. 2010; 46:506-534.

Knight J, Gunatilaka R. Does Economic Growth Raise Happiness in China? Oxford Development Studies. 2011; 39:1-24.

Knight J, Song L, Gunatilaka R. Subjective Well-being and Its Determinants in Rural China. China Economic Review. 2009; 20:635-649.

Levinson A. Valuing Public Goods Using Happiness Data: The Case of Air Quality. Journal of Public Economics. 2012; 96:869-880.

Li Z, Folmer H, Xue J. To What Extent Does Air Pollution Affect Happiness? The Case of the Jinchuan Mining Area, China. Ecological Economics. 2014; 99:88-99.

He, Jiaxiu, Liu, Haoming, Salvo, Alberto. Severe Air Pollution and Labor Productivity: Evidence from Industrial Towns in China. 2016. IZA Discussion Paper 8916

Kampa M, Castanas E. Human Health Effects of Air Pollution. Environmental Pollution. 2008; 151:362-367. [PubMed: 17646040]

Luechinger S. Valuing Air Quality Using the Life Satisfaction Approach. Economic Journal. 2009; 119:482-515.

Luechinger S. Life Satisfaction and Transboundary Air Pollution. Economics Letters. 2010; 107:4-6.

MacKerron, George, Mourato, Susana. Life Satisfaction and Air Quality in London. Ecological Economics. 2009; 68:1441-1453.

Marcotte, Dave E. Something in the Air? Pollution, Allergens and Children's Cognitive Functioning. 2016. IZA Discussion Paper No. 9689

Menz, Tobias, Welsch, Heinz. Population aging and environmental preferences in OECD countries: The case of air pollution. Ecological Economics. 2010; 69:2582-2589.

Menz T. Do People Habituate to Air Pollution? Evidence from International Life Satisfaction Data. Ecological Economics. 2011; 71:211-219.

Nattero G, Enrico A. Outdoor Pollution and Headache. Headache. 1996; 36:243-245. [PubMed: 8675430]

Pal, Chandan, Bengtsson-Palme, Johan, Kristiansson, Erik, Joakim Larsson, DG. The Structure and Diversity of Human, Animal and Environmental Resistomes. Microbiome. 2016; 4(1):4-54. [PubMed: 26796629]

Rehdanz K, Maddison D. Local Environmental Quality and Life-satisfaction in Germany. Ecological Economics. 2008; 64:787-797.

Smith VK, Huang JC. Can Markets Value Air Quality? A Meta-analysis of Hedonic Property Value Models. Journal of Political Economy. 1995; 103(1):209-227.

Stanek LW, Brown JS, Stanek J, Gift J, Costa DL. Air pollution toxicology-a brief review of the role of the science in shaping the current understanding of air pollution health risks. Toxicological sciences: an official journal of the Society of Toxicology. 2011; 120(Suppl 1):S8-27. [PubMed: 21147959]

Sun, Chuanwang, Yuan, Xiang, Tao, Xin. Social Acceptance towards the Air Pollution in China: Evidence from Public's Willingness to Pay for Smog Mitigation. Energy Policy. 2016; 92:313324.

Tanaka S. Environmental Regulations on Air Pollution in China and Their Impact on Infant Mortality. Journal of Health Economics. 2015; 42:90-103. [PubMed: 25868145]

The Economist. Mapping the Invisible Scourge. 2015 Aug 15.

Vasquez, William F., Mozumder, Pallab, Hernandez-Arce, Jesus, Berrens, Robert P. Willingness to Pay for Safe Drinking Water: Evidence from Parral, Mexico. Journal of Environmental Management. 2009; 90:3391-3400. [PubMed: 19525059]

Wang, Hua, Shi, Yuyan, Kim, Yoonhee, Kamata, Takuya. Valuing Water Quality Improvement in China: A Case Study of Lake Puzhehei in Yunnan Province. Ecological Economics. 2013; 94:5665 . 
Wang, Hua, Xie, Jian, Li, Honglin. Water Pricing with Household Surveys: A Study of Acceptability and Willingness to Pay in Chongqing, China. China Economic Review. 2010; 21:136-149.

Wang, Keran, Wu, Jinyi, Wang, Rui, Yang, Yingying, Chen, Renjie, Maddock, Jay E., Lu, Yuanan. Analysis of Residents' Willingness to Pay to Reduce Air Pollution to Improve Children's Health in Community and Hospital Settings in Shanghai, China. Science of the Total Environment. 2015; 533:283-289. [PubMed: 26172595]

Welsch H. Environment and Happiness: Valuation of Air Pollution Using Life Satisfaction Data. Ecological Economics. 2006; 58:801-813.

Welsch H. Environmental Welfare Analysis: A Life Satisfaction Approach. Ecological Economics. 2007; 62:544-551.

Wolfson E. Your Zodiac Sign, Your Health. The Atlantic. 2013 Nov 15.

Yusuf, Arief Anshory, Resosudarmo, Budy P. Does Clean Air Matter in Developing Countries' Megacities? A Hedonic Price Analysis of the Jakarta Housing Market, Indonesia. Ecological Economics. 2009; 68:1398-1407.

Zhai, Guofang, Suzuki, Takeshi. Public Willingness to Pay for Environmental Management, Risk Reduction and Economic Development: Evidence from Tianjin, China. China Economic Review. 2008; 19:551-566.

Zhang, Xin, Zhang, Xiaobo, Chen, Xi. Happiness in the Air: How Does a Dirty Sky Affect Subjective Well-being?. 2015. IZA DP No. 9312

Ziebarth, NR., Schmitt, M., Karlsson, M. The Short-Term Population Health Effects of Weather and Pollution: Implications of Climate Change. 2013. IZA Discussion Paper No. 7875 


\section{Table 1}

Summary statistics of key variables

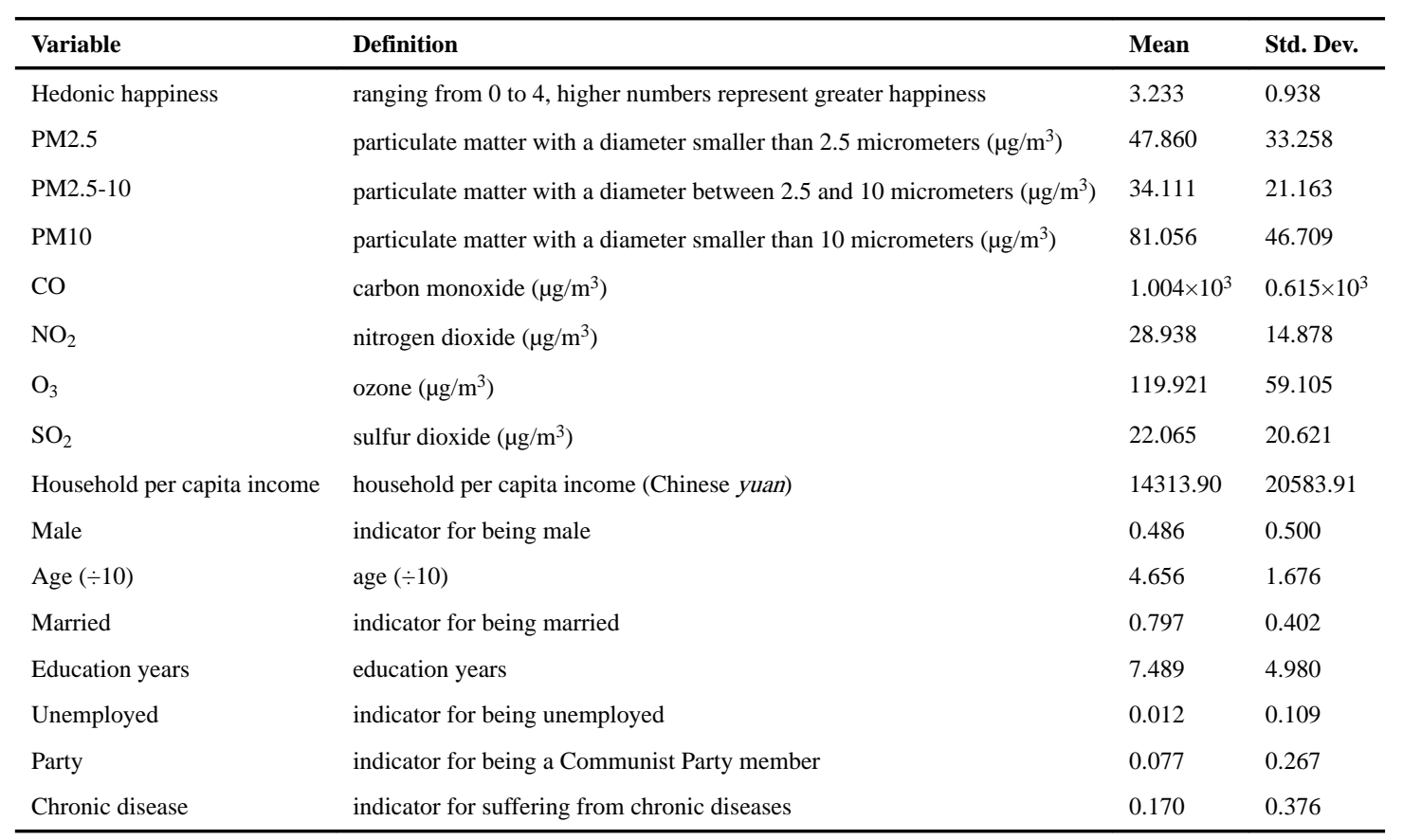

Source: China Family Panel Studies 2014. 


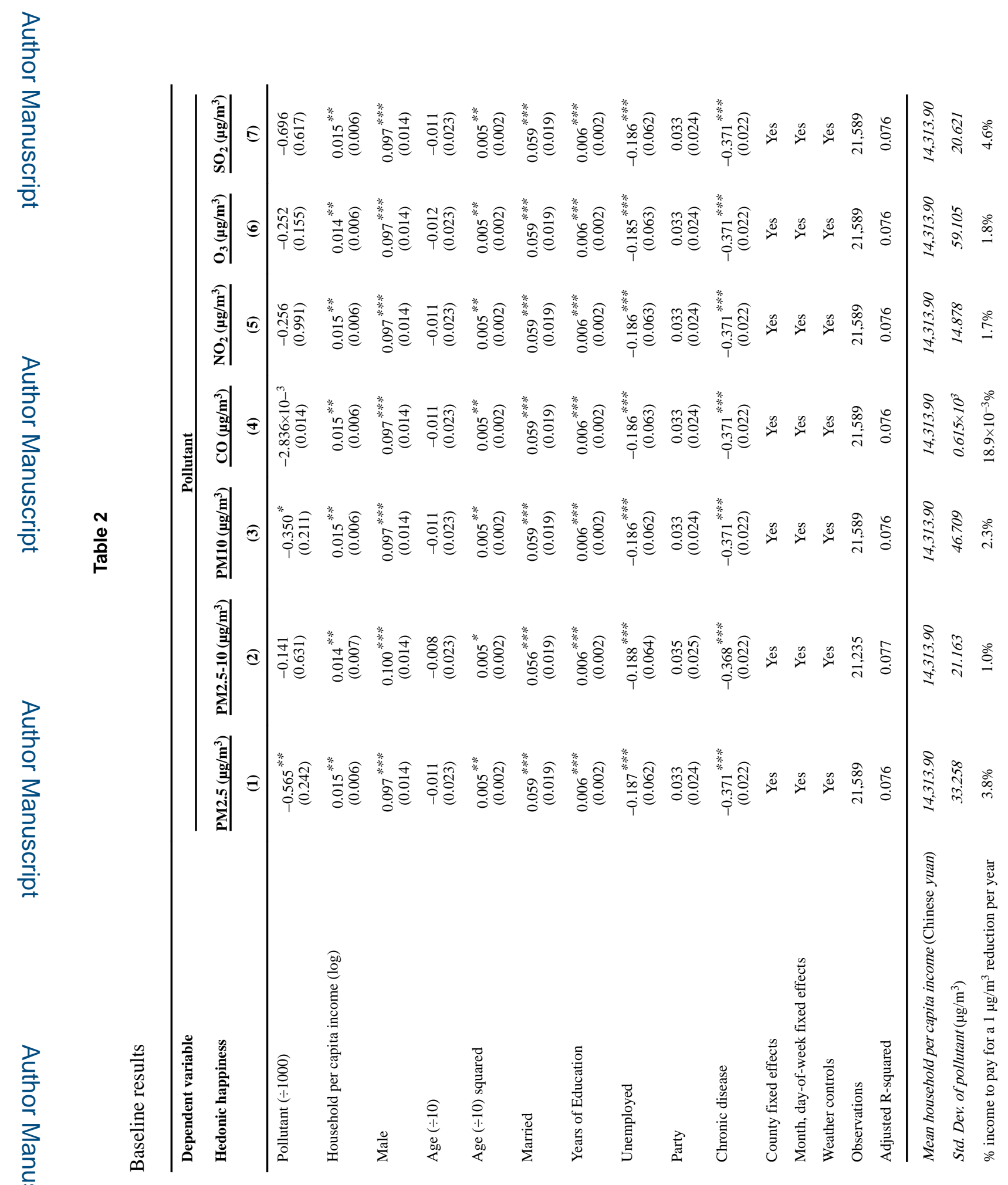




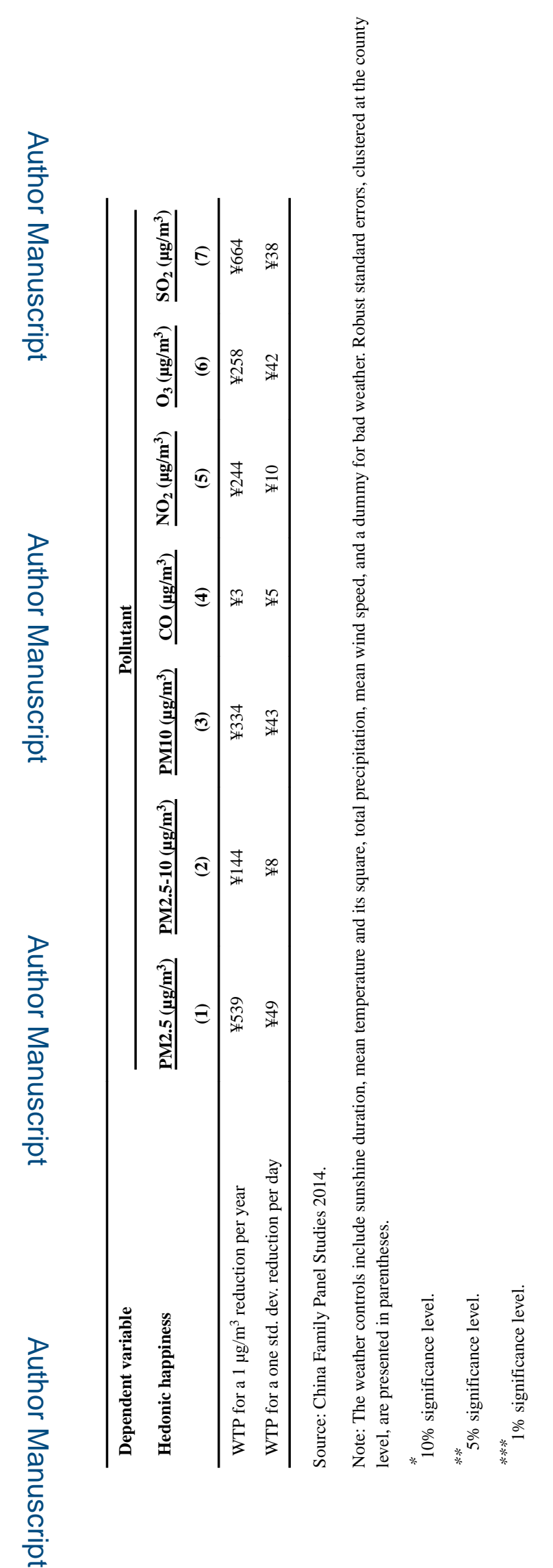




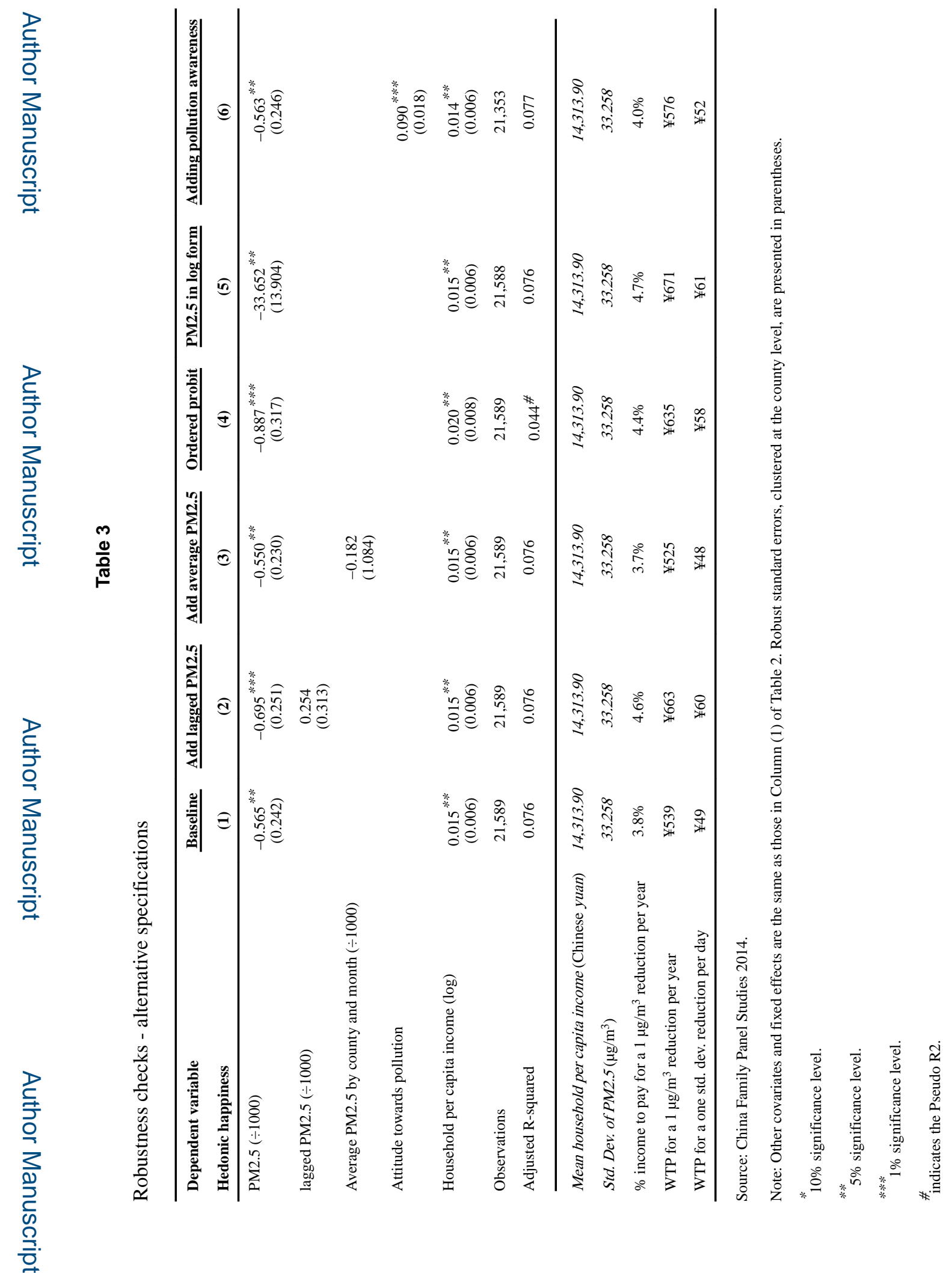



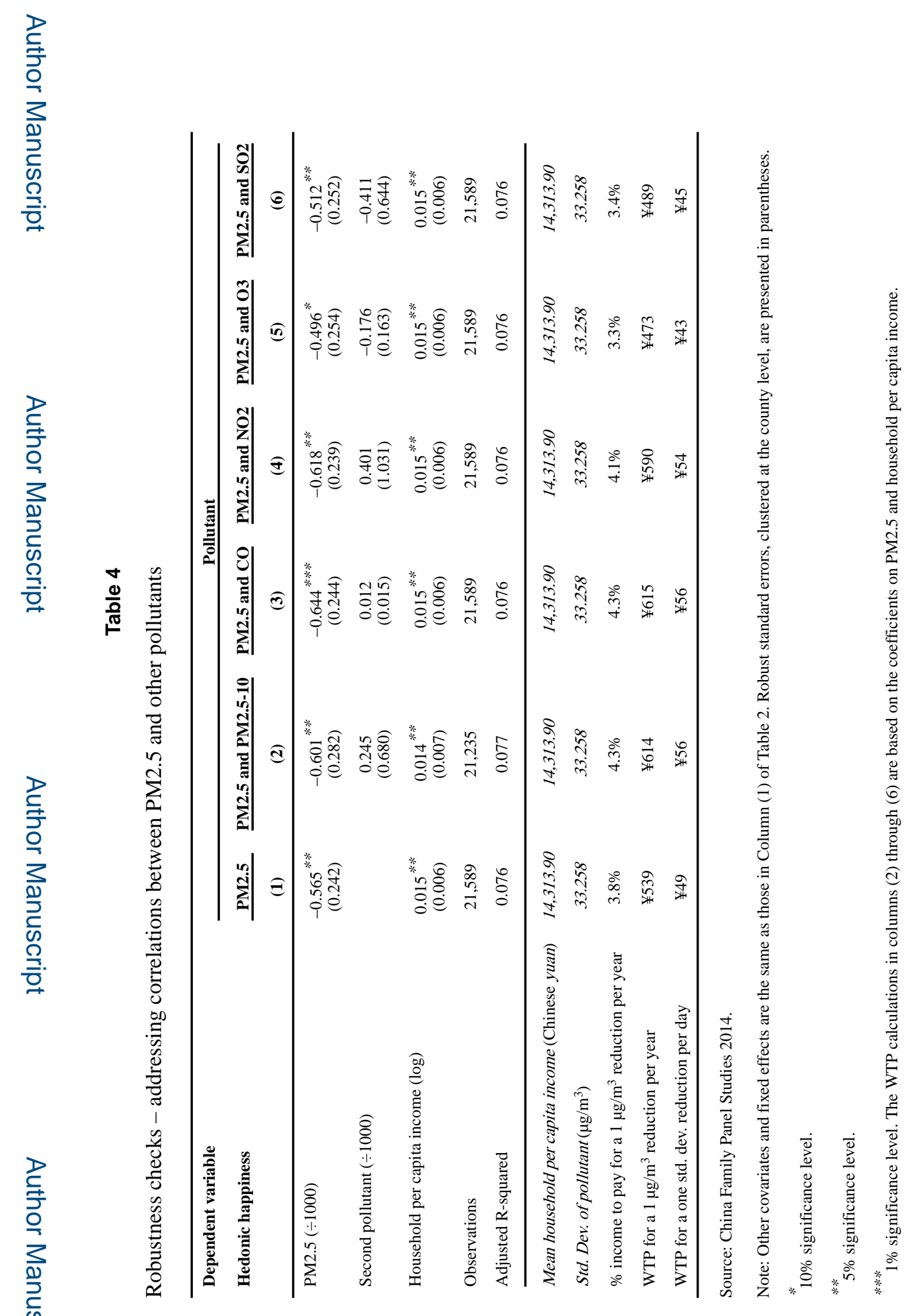


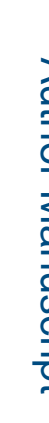

م)

ב己

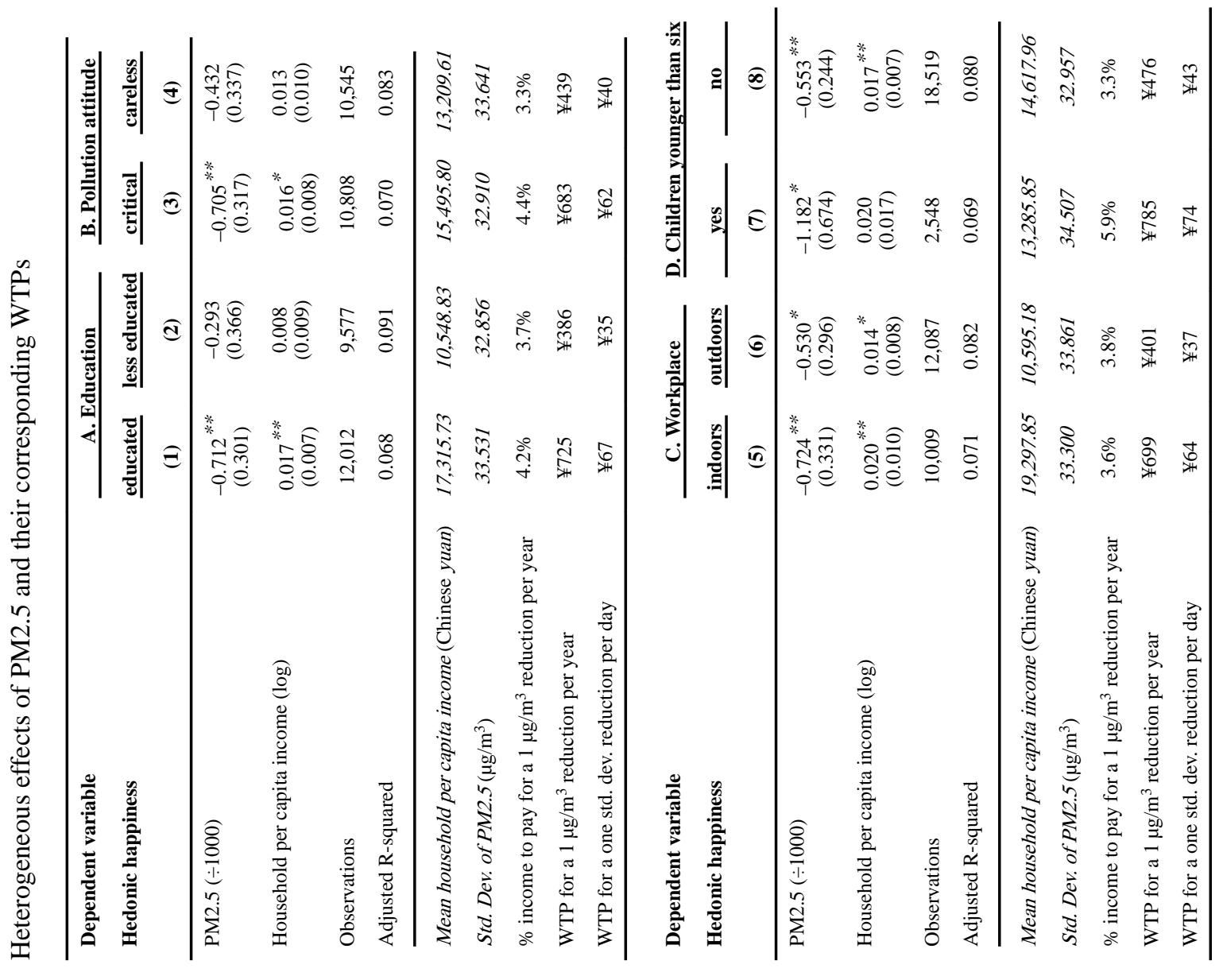
Ecol Econ. Author manuscript; available in PMC 2018 July 01 

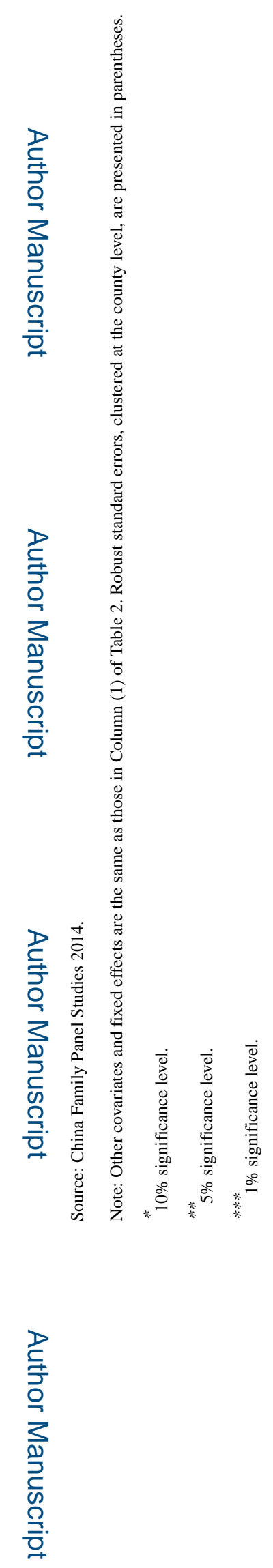

Ecol Econ. Author manuscript; available in PMC 2018 July 01. 